Noman 2019, 37(2), 35-42

Revista de Psicologia, Ciències de l'Eduació i de l'Esport

ISSN: $1138-3194$

CFacultat de Psicologia, Ciències de l'Educació i de l’Esport Blanquerna

Universitat Ramon Llull

\title{
Influence of flipped classroom methodology on the self-concept of primary education students
}

\author{
Héctor Galindo-Domínguez \\ University of Deusto
}

Received: 2019-5-5

Accepted: 2019-10-2 Influence of flipped classroom methodology on the self-concept of primary education
students

\begin{abstract}
Summary. Flipped classroom is an educational methodology whereby students complete the most theoretical part of a lesson at home, usually by viewing educational videos or using other similar tools. This allows them to dedicate more class time to developing higher order thinking skills via the completion of practical tasks. Since its introduction in the classroom few years ago, the number of primary education teachers using the method has increased steadily, but teachers sometimes lack reliable data on its effectiveness. The objective of this research was to address this by analysing how the methodology affects primary education students' self-concept. To this end, data were collected on 822 students (Age = 10.84; SD = .873), who were divided into a control group (437 students) and an experimental group (385 students). The experimental group underwent a 7-month flipped classroom intervention. Both groups completed the AF-5 scale before and after the intervention. The results suggest, firstly, that the flipped classroom methodology neither significantly improved nor significantly worsened any of the dimensions of selfconcept more than the group that did not apply this methodology. Meanwhile, however, both groups did show improvements in the social, emotional and family dimensions of their self-concept. The paper concludes with a discussion of these outcomes and suggestions for future research topics.
\end{abstract}

Keywords: flipped classroom; primary education; self-concept; intervention; effectiveness.

Influencia de la metodología de flipped classroom en el autoconcepto de los estudiantes de educación primaria

Resumen. El flipped classroom es una metodología que consiste en mover la parte más teórica de una clase a casa, generalmente a través de vídeos educativos o herramientas similares, y dedicar el tiempo en clase a actividades de pensamiento de orden superior. Desde su introducción en las aulas hace unos años, cada vez más docentes de educación primaria la aplican, pero tal vez, sin conocer su efectividad. Por ello, el objetivo de este estudio es conocer la efectividad de esta metodología sobre el autoconcepto de estudiantes de educación primaria. Para ello formaron parte del estudio 822 estudiantes (Edad $=10.84$; DT $=.873$ ), divididos en un grupo control (437 estudiantes) y en un grupo experimental (385 estudiantes). Este último grupo se sometió a una intervención Flipped Classroom de 7 meses de duración. Ambos grupos rellenaron la escala AF-5, tanto al inicio como al término de la intervención. Los resultados demuestran que el flipped classroom no mejoraron ni empeoraron significativamente ninguna de las dimensiones del autoconcepto, salvo el grupo que no aplicó esta metodología. Por otra parte, ambos grupos mejoraron el autoconcepto social, emocional y familiar. Finalmente, se discuten estos resultados y se indican futuras temáticas de investigación.

Palabras clave: Flipped Classroom; educación primaria; autoconcepto; intervención; efectividad

Correspondence

Héctor Galindo-Domínguez

Psychology and Education Faculty, University of Deusto

Avenida de las universidades, 24, 48007, Bilbao (España);

688602315

hector.galindo@opendeusto.es 


\section{Introduction}

The flipped classroom, also widely known as the inverted classroom, is a methodology used in the educational field. It involves moving the traditional lesson outside the classroom, generally via the use of electronic tools such as educational videos, podcasts, presentations or readings. This allows teachers to focus more on assignments with practical application in the classroom (Arnold-Garza, 2014). In other words, class time is devoted to practical activities or learning projects related to problem solving (Lai \& Hwang, 2016).

In the flipped classroom methodology, students are expected to work at home on tasks requiring low order thinking skills such as remembering and understanding tasks. They are then asked to complete activities involving medium and high order thinking skills like applying, analysing, evaluating and creating tasks in the classroom (Ruiz, Sánchez-Rodríguez \& Sánchez-Rivas, 2014; Hwang, Lai \& Wang, 2015)

According to some experts, the flipped classroom is a potentially beneficial methodology in that it helps students develop some of the key competencies for $21^{\text {st }}$ century education, including communication, critical thinking, creativity and problem solving, as long as students are provided with a suitable environment where they can learn by asking questions about important aspects (Hwang, Lai \& Wang, 2015; Prieto, 2017)

Although the global spread of the notion of the flipped classroom has usually been attributed to Bergmann and Sams, it should be noted that this methodology has long existed under a number of other guises. For example, nearly 20 years ago Baker (2000) and Lage, Platt \& Treglia (2000) were already applying some of the basic principles of flipped classroom methodology in order to adapt their classes to their students' needs.

A content analysis of the prevalence of the term, however, reveals that since the landmark publication by Bergmann and Sams (2012) the quantity of research into this methodology has grown exponentially (Uzunboylu \& Karagözlü, 2017). This mushrooming of interest could lead us to think that flipped classroom methodology is not only being investigated more, but also that it is being used increasingly often by teachers and educators. It is true that this method is mainly used in higher educational or with students in the final years of high school, maybe because students at these levels have already developed certain skills (autonomy, technological competence, responsibility, etc.). Nonetheless, the methodology's popularity is also expanding, albeit more slowly, amongst primary education teachers (Uzunboylu \& Karagözlü, 2017; Galindo-Dominguez, 2018).

It stands to reason that as a greater number of primary education teachers have begun to employ flipped classroom techniques, there is a growing need for research into the implications of the use of the methodology at this educational level. In this regard, it is remarkable that the vast majority of existing studies have mainly followed the same path, largely focusing on the effect of this methodology on academic performance
(Galindo-Dominguez, 2018). The degree to which the flipped classroom may be associated with improvements in students' performance is the subject of controversy owing to the disparity of results. To be more precise, while some researchers have concluded that the method has positive results (Aidinopoulou \& Samspon, 2015; Tsai, Shen \& Lu, 2015; Mohanty \& Parida, 2016; Eryilmaz \& Ahmed, 2017; Toh, Tengah, Shahrill, Tan \& Leong, 2017), others have found neutral or negative results (Tao, Huang \& Tsai, 2016; Feriz, Sebastià \& García, 2017). In other words, there is no clear scholarly consensus about this topic.

Meanwhile, other studies have discussed the effects of this methodology on different psychological constructs. For instance, there are some positive findings with regard to the association between the use of the flipped classroom and improvements in self-confidence (Chun \& Heo, 2018), self-efficacy (Ibrahim, 2014; Mohammed, 2017; Chou, 2018), motivation (Xin-Yue, 2016; Díaz-Garrido, Martín-Peña \& Sánchez-López, 2017; Alsancak \& Özdemir, 2018) and self-regulation (Lai \& Hwang, 2016; Moos \& Bonde, 2016; Sedraz et al., 2018). However, other studies have found no statistically significant relationship between the methodology and improvements in self-efficacy, self-regulation and motivation (Ferriz et al, 2017; Chun \& Heo, 2018).

In light of the considerable number of studies suggesting that this methodology can be effective at improving a range of different psychological constructs, the authors believe it is of interest to analyse the impact of flipped classroom use on students' self-concept.

Firstly, as has been seen throughout this theoretical framework, flipped classroom students have more class time to perform practical activities that require collaboration. This collaboration could lead to improvements in their social self-concept, as it is likely to make them more conscious of their social acceptance and their social competences. In addition, as the overwhelming majority of studies support the idea that the use of the flipped classroom improves self-efficacy. Being able to carry out a certain task successfully could lead one to have a better perception of one's own academic abilities. Therefore, it seems reasonable to assume that using this methodology could improve academic self-concept.

Secondly, as their homework consists mainly of viewing educational videos, it is likely that students will have more time to spend with their families, and consequently their perceptions of their families might improve.

Finally, the improvement in these dimensions of self-concept could lead to an improvement in the students' emotional self-concept.

\section{Method}

\section{Objective}

The main objective of this research is to study the effects of flipped classroom methodology on the selfconcept of primary education students. 


\section{Sample and Context}

The sample in this research was made up of 822 primary education students (Age $=10.84 ; \mathrm{SD}=.873)$, who were divided into two groups, an experimental group and a control group. The students were in their fourth, fifth and sixth years of primary education. All the schools they attended were state-subsidised primary schools in Spain, with the exception of one public school that contributed students to the experimental group. The student bodies in all the schools came largely from middle-class socioeconomic backgrounds. The schools were all located in urban areas, with the exception of one school in a more rural area that contributed members to the experimental group.

The experimental group was made up of 385 students (Age $=10.87 ; S D=.827), 186$ boys and 199 girls. $31(8.1 \%)$ of them were in fourth grade, $93(24.2 \%)$ fifth grade and $261(67.8 \%)$ sixth grade.

The control group was made up of 437 students (Age $=10.81 ; S D=.912), 223$ boys and 214 girls. 67 (15.3\%) of them were in fourth grade, 117 (26.8\%) fifth grade and $253(57.9 \%)$ sixth grade.

\section{Intervention}

The students in the experimental group underwent a flipped classroom intervention lasting two school terms, from September 2018 to April 2019. The teachers of the students in the experimental group $(n=13)$ were very familiar with this methodology, as all of them had been using it for a year or more $(M=3.23$; $S D=$ .926). Nonetheless, so as to verify that the experimen- tal group teachers were indeed using flipped classroom methodology, their interventions were assessed using a five-point ad-hoc Likert questionnaire based on the Flipped Learning Network's standards (FLN, 2012). In this questionnaire, shown in Table 1, teachers were asked whether they had carried out some basic actions in order to ensure that their activities met the criteria for flipped classroom interventions.

Ultimately, all the experimental group teachers ( $\mathrm{n}$ $=13$ ) were included in the sample, as their classes were found to meet the criteria for flipped classrooms, as is evident from the means and standard deviations for each analysed dimension shown. To be more exact, the scores for the dimensions Flexible environment $(M=$ 4.38; $S D=.664)$, Learning Culture $(M=4.46 ; S D=.365)$, Intentional Content $(M=4.14 ; S D=.325)$ and Professional Educator $(M=4.25 ; S D=.540)$ were all above 4 out of 5 points, which indicates a good degree of adaptation to a flipped classroom.

The teachers combined flipped classroom activities with other methodologies, such as cooperative learning (100\%), gamification (92\%), project-based learning (53.8\%), visual thinking (15.3\%), lectures (.07\%) and number-based learning (.07\%). The group was made up of six maths teachers, three natural sciences teachers, two who were teaching other languages (Basque, Catalan, Galician, English...), one who was teaching Spanish, and one who was teaching social studies.

Meanwhile, the control group also underwent an intervention over the course of two school terms, from September 2018 to April 2019, but they did not use any flipped classroom methodology. In primary educa-

Table 1. Ad-Hoc questionnaire about the usage of Flipped Classroom techniques in Primary Education

\begin{tabular}{|c|c|}
\hline \multicolumn{2}{|l|}{ Flexible Environment } \\
\hline Temporal and spatial flexibility & I have left spaces and a reasonable amount of time for each student to view the proposed videos outside school. \\
\hline Accessibility & $\begin{array}{l}\text { I have used different methods (Moodle, USB...) so that each student can access the videos by themselves outside } \\
\text { school }\end{array}$ \\
\hline $\begin{array}{l}\text { Adaptability and personalization of } \\
\text { learning }\end{array}$ & $\begin{array}{l}\text { When I have observed that my students have not understood the content of a video correctly, I have tried to adapt } \\
\text { to them and I have modified the pace of learning. }\end{array}$ \\
\hline \multicolumn{2}{|l|}{ Learning Culture } \\
\hline Responsibility & I have made my students see the importance of doing homework in order to progress in their learning process. \\
\hline Autonomy & $\begin{array}{l}\text { I believe that working in this way has allowed my students to realize that they are able to work and learn more on } \\
\text { their own. }\end{array}$ \\
\hline Self-Improvement & $\begin{array}{l}\text { After a group discussion of the ideas of the videos, I have allowed my students to realize their mistakes and correct } \\
\text { them. }\end{array}$ \\
\hline Meaningful activities & $\begin{array}{l}\text { After my students mastered the content of the videos, I have assigned my students meaningful activities involving } \\
\text { medium- and higher-order thinking (applying, analysing, creating or evaluating. }\end{array}$ \\
\hline \multicolumn{2}{|l|}{ Intentional Content } \\
\hline Duration & The duration of the videos I have used was less than 2 minutes \\
\hline Voice & The narration in the videos that I have used has been animated, not monotonous. \\
\hline Humour & $\begin{array}{l}\text { In order to catch the better attract students' attention to strategic points of the video I sought out/created videos in } \\
\text { which humour is used in some parts. }\end{array}$ \\
\hline Relevance and accuracy & The topic of the videos was explained as concisely as possible. \\
\hline Reminders & The videos I have used included some notes with the aim of clarifying some key ideas. \\
\hline Complementary tools & $\begin{array}{l}\text { I have used a tool (Edpuzzle, Plickers...) to complement the video itself and determine whether students have } \\
\text { absorbed the content. }\end{array}$ \\
\hline \multicolumn{2}{|l|}{ Professional Educator } \\
\hline Interpretation of the environment & I have analysed, evaluated and interpreted my students' marks through the watched videos. \\
\hline Feedback & $\begin{array}{l}\text { After evaluating the results obtained through both videos and class activities, I have provided feedback to each } \\
\text { student. }\end{array}$ \\
\hline Elimination of lectures & $\begin{array}{l}\text { After having replaced the most theoretical part of the face-to-face class with the videos, I have used lecture } \\
\text { methodology only when I have observed severe difficulties. }\end{array}$ \\
\hline Reflection on teaching practice & $\begin{array}{l}\text { Based on the mistakes made by my students, both, in class and in the evaluation of the videos, I have self-evaluated } \\
\text { and I have rethought and modified my practice (sent videos and activities, tasks in class, ways of providing } \\
\text { feedback...), so as to improve the quality of my classes. }\end{array}$ \\
\hline
\end{tabular}


tion, it is extremely difficult to find teachers who use only traditional methodologies. That is why teachers in this group $(n=11)$ reported using a range of methodologies: cooperative learning $(81.8 \%)$, project-based learning $(63.6 \%)$, visual thinking $(27.2 \%)$ lectures $(18.1 \%)$, thinking routines $(18.1 \%)$, peer tutoring $(.09 \%)$, expert groups (.09\%), number-based learning $(.09 \%)$, research $(.09 \%)$ and field trips $(.09 \%)$. In this group, there were three teachers teaching natural sciences, two teaching Spanish, two teaching maths, two teaching other languages (Basque, Catalan, Galician, English...), one teaching social sciences and one teaching physical education.

The teachers in both groups followed the official Spanish primary education curriculum for the subjects they were teaching or the adaptation of the curriculum applicable in their respective autonomous communities.

\section{Research Tools}

In order to measure the self-concept of the students, the AF-5 scale (García \& Musitu, 2014) was used. This scale consists of 30 items answered on a five-point Likert scale and is divided into five factors:

Academic self-concept: Academic self-concept is the perception and evaluation that a student has of his or her academic abilities (Marsh \& Rhonda, 2002). This factor is determined by items $1,6,11$, 16,21 and 26.

Social self-concept: social self-concept is defined as a person's perception of their acceptance by their peers (social acceptance), as well as a person's performance with regard to social relations, social skills and sociability (social competence) (FernándezZabala, Rodríguez-Fernández \& Goñi, 2016). This factor is determined by items 2,7,12,17,22 and 27 .

Emotional self-concept: Emotional self-concept is the perception that a student has of his or her emotional status and his or her response to specific situations (García \& Musitu, 2001). This factor is determined by items 3,8,13, 18, 23 and 28 .

Family self-concept: Family self-concept is the perception that a student has of his or her implication, participation and integration in the family environment. (García \& Musitu, 2001). This factor is determined by items 4, 9, 14, 19, 24 and 29.

Physical self-concept: The physical self-concept is the perception that a student has of his or her physical appearance and condition (García \& Musitu, 2001). This factor is determined by items $5,10,15,20,25$ and 30.

\section{Procedure}

Initially, in September 2018, consent was obtained and the instrument was prepared in order to carry out the present study. As we are dealing with underage students, parents signed and returned to the corresponding tutors an informed consent document in which the objective and the procedure of this study were described.

The questionnaire was completed online during school hours, first in September 2018 and then in April 2019. Each time the questionnaire was administered, the students were given about 40 minutes to complete it. It should be noted that all the data collected met the minimum requirements for privacy and anonymity of the students. This was possible thanks to a code system agreed upon by the researches and teachers.

\section{Data analysis}

Two different methods were used to analyse the collected data. First, SPSS Statistics 24 was used to adjust reversed items, observe descriptive statistics, correlations, reliability values and ANOVAs. Later, SPSS AMOS 24 was used to confirm model fit and conduct invariance analysis.

\section{Results}

The data analysis process started with some preliminary adjustments to the data. For example, negative items were reverted. Specifically, all the items measuring emotional self-concept factor are inverted (e.g.: I get nervous when my teacher calls on me). For this study, it was necessary to invert these items, because as the items in this factor are formulated, they really measure a lack of emotional self-concept.

Firstly, the factorial invariance was analysed and assessed depending on the key variable in this study: the intervention group. Four different models were compared. Model 1 was an unconstrained model, in which the equivalence of fixed and free parameters was assessed. Model 2 assessed weak factorial invariance through the equivalence of factor loadings. Model 3 evaluated strong factorial invariance through the equivalence of intercepts, and Model 4 assessed strict factorial invariance through the equivalence of residual variance and error covariance.

As shown in Table 2, the data revealed that it was possible to maintain the factorial invariance by groups for both the pre- and post-intervention measurements, as the values of Comparative Fit Index (CFI) did not fluctuate by more than .01 (Cheung \& Rensvold, 2002). In addition, the values of RMSEA and AIC hardly changed at all. Nonetheless, it is worth noting that in the pre-intervention test, the CFI of Model 4 was above the critical value of .01 (CFI = -.011).

These data prove that it was not necessary to divide the statistical analyses by group, due to the equivalence of the two cohorts.

Afterwards, the model fit was assessed in both models and for both the first measurement (pre-intervention) and the second measurement (post-intervention). Model fit was assessed using the maximum likelihood method. The critical values for the evaluation of models were those indicated by Hooper, Coughlan and Mullen (2008), suggesting good model fit of 
Table 2. Factorial invariance models depending on the group

\begin{tabular}{|c|c|c|c|c|c|c|c|c|c|c|c|}
\hline & & $\chi^{2} / g 1$ & $\Delta \chi^{2} / \mathrm{gl}$ & CFI & $\Delta \mathrm{CFI}$ & TLI & $\Delta \mathrm{TLI}$ & RMSEA & $\triangle$ RMSEA & AIC & $\Delta \mathrm{AIC}$ \\
\hline \multirow[t]{4}{*}{ Pre } & 1 & 2.316 & - & .858 & - & .844 & - & .040 & - & 2229.746 & - \\
\hline & 2 & 2.337 & .021 & .851 & -.007 & .841 & -.003 & .040 & .000 & 2254.492 & 24.74 \\
\hline & 3 & 2.332 & -.005 & .846 & -.005 & .842 & .001 & .040 & .000 & 2260.855 & 6.36 \\
\hline & 4 & 2.362 & .03 & .835 & -.011 & .838 & -.004 & .041 & .001 & 2302.479 & 41.62 \\
\hline \multirow[t]{4}{*}{ Post } & 1 & 2.289 & - & .856 & - & .859 & - & .040 & - & 2237.470 & - \\
\hline & 2 & 2.289 & .000 & .856 & .000 & .859 & .000 & .040 & .000 & 2237.470 & .000 \\
\hline & 3 & 2.289 & .000 & .856 & .000 & .859 & .000 & .040 & .000 & 2237.470 & .000 \\
\hline & 4 & 2.289 & .000 & .856 & .000 & .859 & .000 & .040 & .000 & 2237.470 & .000 \\
\hline
\end{tabular}

Note: Model $1($ Configural $)=$ Unconstrained model; Model 2 (loadings) $=$ Model $1+$ equal factorial loadings; Model 3 (Intercepts) $=$ Model $2+$ Equal intercepts; Model 4 (Residual) $=$ Model 3 + equal residual variances and error covariances.

Table 3. Correlation between the main dimensions at both moments

\begin{tabular}{|c|c|c|c|c|c|c|c|c|c|c|c|}
\hline & & \multicolumn{5}{|c|}{ Pre phase $(\alpha=.858)$} & \multicolumn{5}{|c|}{ Post phase $(\alpha=.864)$} \\
\hline & & $\mathrm{AC}$ & so & EM. & FM. & PH. & $\mathrm{AC}$ & So & EM. & FM. & PH. \\
\hline \multirow[t]{5}{*}{ Pre phase } & AC. & $(.846)$ & $.362^{\star *}$ & $.207^{* *}$ & $.401^{\star \star}$ & $.474^{\star *}$ & $.650^{* *}$ & $.197^{* *}$ & $.186^{* *}$ & $.279^{\star *}$ & $.313^{* *}$ \\
\hline & SO. & & $(.671)$ & $.336^{* *}$ & $.322^{\star *}$ & $.511^{* *}$ & $.290^{* *}$ & $.581^{* *}$ & $.238^{* *}$ & $.251^{* *}$ & $.379^{* *}$ \\
\hline & EM. & & & $(.747)$ & $.210^{\star *}$ & $.196^{\star \star}$ & $.185^{\star *}$ & $.252^{* *}$ & $.541^{* *}$ & $.147^{\star *}$ & $.178^{* *}$ \\
\hline & FM. & & & & $(.670)$ & $.309^{* *}$ & $.338^{\star *}$ & $.233^{* *}$ & $.137^{\star \star}$ & $.473^{\star *}$ & $.217^{\star *}$ \\
\hline & PH. & & & & & $(.716)$ & $.334^{\star *}$ & $.365^{* *}$ & $.169^{\star *}$ & $.249^{* *}$ & $.663^{* *}$ \\
\hline \multirow[t]{5}{*}{ Post phase } & AC. & & & & & & $(.862)$ & $.283^{* *}$ & $.242^{\star *}$ & $.372^{\star *}$ & $.420^{* *}$ \\
\hline & $\underline{\text { SO. }}$ & & & & & & & $(.693)$ & $.360^{\star *}$ & $.303^{* *}$ & $.483^{* *}$ \\
\hline & EM. & & & & & & & & $(.755)$ & $.191^{\star *}$ & $.214^{* *}$ \\
\hline & FM. & & & & & & & & & $(.753)$ & $.303^{* *}$ \\
\hline & PH. & & & & & & & & & & $(.751)$ \\
\hline
\end{tabular}

Note: AC.: Academic self-concept; SO.: Social self-concept; EM.: Emotional self-concept; FM.: Family self-concept; PH.: Physical self-concept. * p <.050; ** p<.001; Cronbach's $\alpha$ values are shown on the main diagonal of the matrix.

models with $\mathrm{X}^{2} / d f$ values lower than 5.0; higher values around .90 in the Tucker-Lewis Index (TLI), Incremental Fit Index (IFI) and Comparative Fit Index (CFI); lower values than .06 in the Root Mean Square Error of Approximation (RMSEA) and values as small as possible in the Akaike Information Criterion (AIC).

In this sense, it is worth highlighting that both models' fit in the pre-intervention phase $\left(\mathrm{X}^{2} / d f=3.23\right.$; $\mathrm{NFI}=.832 ; \mathrm{TLI}=.864 ; \mathrm{IFI}=.877 ; \mathrm{CFI}=.877 ; \mathrm{RMSEA}=$ $.052 ; \mathrm{AIC}=1475.788)$ as in the post phase $\left(\mathrm{X}^{2} / d f=3.24\right.$; $\mathrm{NFI}=.844 ; \mathrm{TLI}=.875 ; \mathrm{IFI}=.887 ; \mathrm{CFI}=.886 ; \mathrm{RMSEA}=$ .052 ; AIC $=1481.592$ ) were appreciably good, especially considering that the answers came from kids. Specifically, the absolute fit indices and parsimony fit indices were good. However, the main problem with the model came from incremental indices with values below .90. While it is true that these values were very similar to those found in other studies analysing the psychometric properties of the instrument used in other kinds of samples (e.g. Esnaola, Rodríguez \& Goñi, 2011), it was deemed necessary to inspect the factorial loadings of the items to identify the items that had made a poor contribution to a good model fit.

The results showed that five main items had caused problems in the pre- and in the post-phase. The most critical ones were item 04 ("I am often criticised at home") and item 22 ("I find it difficult to speak to strangers"), with factorial loadings of $\lambda_{\text {i04(pre) }}=.29$, $\lambda_{\mathrm{i} 04 \text { (post) }}=.43$ and $\lambda_{\mathrm{i} 22 \text { (pre) }}=.18, \lambda_{\mathrm{i} 22 \text { (post) }}=.25$. In addition, item 03 ("I am afraid of some things"), item 13 ("I get scared easily") and item 15 ("I consider myself elegant") also had factorial loadings below .50, but they were close to this critical value. The factorial loadings of these items were $\lambda_{\text {i03(pre) }}=.49, \lambda_{\text {i03(post) }}=.41$; for item 03; $\lambda_{\text {i13(pre) }}=.46, \lambda_{\text {i13(post) }}=.47$ for item 13 and $\lambda_{\text {i15(pre) }}=.47$, $\lambda_{\text {i15(post) }}=.49$ for item 15 .

Apart from these five items, item 14 ("My family is disappointed with $\mathrm{me}^{\prime \prime}$ ) only had a value below .50 $\left(\lambda_{\text {i14(pre) }}=.34\right)$ in the pre-intervention phase, and item 17 ("I am a happy person") only had a value below .50 $\left(\lambda_{i 17 \text { (post) }}=.47\right)$ in the post-intervention phase.

It is thought that these items might have displayed values below .50 because some words, such as "criticized, elegant, be disappointed, etc., might have been difficult for primary education students to understand.

Finally, to conclude the discussion of these preliminary adjustments, illustrated in Table 3, the correlation and internal consistency of the dimensions used were studied.

It is clear from this analysis that all the dimensions of self-concept correlated positively and significantly with each other and that the reliability of the scale and the dimensions in the pre- and post-intervention phases are good, since the vast majority of values are above .70 (Bonett \& Wright, 2014).

After making these necessary previous adjustments, we went on to analyse data to address the main objective of the study. Firstly, a descriptive analysis was carried out. More specifically, the arithmetic means and standard deviation of each group were observed for each measurement. This information is displayed in Table 4.

Afterwards, through an ANOVA of repeated measures, the effect of the flipped classroom intervention was observed, and then the experimental group was compared with the control group. In order to carry out this analysis, the group variable was considered a be- 
Table 4. Descriptive statistics for each group and phase

\begin{tabular}{|c|c|c|c|c|c|}
\hline & & \multicolumn{2}{|c|}{ Pre Phase } & \multicolumn{2}{|c|}{ Post Phase } \\
\hline & & Means & SD & Means & SD \\
\hline \multirow[t]{2}{*}{$\overline{\mathrm{AC}}$} & Experimental & 4.09 & .641 & 4.11 & .621 \\
\hline & Control & 3.98 & .618 & 4.01 & .645 \\
\hline \multirow[t]{2}{*}{ SO. } & Experimental & 4.14 & .609 & 4.19 & .647 \\
\hline & Control & 4.09 & .626 & 4.15 & .597 \\
\hline \multirow[t]{2}{*}{ EM. } & $\underline{\text { Experimental }}$ & 3.30 & .780 & 3.34 & .802 \\
\hline & Control & 3.19 & .801 & 3.28 & .803 \\
\hline \multirow[t]{2}{*}{ FM. } & $\underline{\text { Experimental }}$ & 4.68 & .432 & 4.72 & .438 \\
\hline & Control & 4.61 & .483 & 4.70 & .447 \\
\hline \multirow[t]{2}{*}{ PH. } & Experimental & 3.97 & .667 & 3.98 & .691 \\
\hline & Control & 3.86 & .669 & 3.85 & .714 \\
\hline
\end{tabular}

Note: AC.: Academic self-concept; SO.: Social self-concept; EM.: Emotional self-concept; FM.: Family self-concept; PH.: Physical self-concept.

Table 5. Test of within-subject contrast for each dimension

\begin{tabular}{|c|c|c|c|c|c|c|c|}
\hline & & SS & df & RMS & F & Sig. & $\eta_{p}^{2}$ \\
\hline \multirow[t]{3}{*}{$\overline{\text { AC. }}$} & Time & .250 & 1 & .250 & 1.774 & .183 & .002 \\
\hline & $\mathrm{T} * \mathrm{G}$ & $<.001$ & 1 & $<.001$ & .001 & .980 & .000 \\
\hline & Error & 115.498 & 820 & .141 & - & - & - \\
\hline \multirow[t]{3}{*}{ SO. } & Time & 1.224 & 1 & 1.224 & 7.598 & .006 & .009 \\
\hline & $\mathrm{T} * \mathrm{G}$ & .007 & 1 & .007 & .042 & .839 & .000 \\
\hline & Error & 132.155 & 820 & .161 & - & - & - \\
\hline \multirow[t]{3}{*}{ EM. } & Time & 1.685 & 1 & 1.685 & 5.762 & .017 & .007 \\
\hline & $\mathrm{T} * \mathrm{G}$ & .242 & 1 & .242 & .828 & .363 & .001 \\
\hline & Error & 239.790 & 820 & .292 & - & - & - \\
\hline \multirow[t]{3}{*}{ FM. } & Time & 1.559 & 1 & 1.559 & 14.477 & .000 & .017 \\
\hline & $\mathrm{T} * \mathrm{G}$ & .245 & 1 & .245 & 2.278 & .132 & .003 \\
\hline & Error & 88.304 & 820 & .108 & - & - & - \\
\hline \multirow[t]{3}{*}{$\overline{\mathrm{PH}}}$. & Time & .001 & 1 & .001 & .006 & .941 & .000 \\
\hline & $\mathrm{T} * \mathrm{G}$ & .058 & 1 & .058 & .357 & .550 & .000 \\
\hline & Error & 132.288 & 820 & .161 & - & - & - \\
\hline
\end{tabular}

Note: AC.: Academic self-concept; SO.: Social self-concept; EM.: Emotional self-concept; FM.: Family self-concept; PH.: Physical self-concept.; T * G: Time * Group; SS: Type III Sum of Squares; RMS: Root mean square.

tween-subject factor, and the phase variable for each dimension of self-concept was considered a withinsubject factor. The results, collected in Table 5, showed some significant findings.

First of all, it is noteworthy that three of the pentafactorial solutions of this instrument were statistically significant with regard to time. This means that, in this study, regardless of group, social self-concept $(p=.006$; $\left.\eta_{p}{ }^{2}=.009\right)$, emotional self-concept $\left(p=.017 ; \eta_{p}^{2}=.007\right)$ and family self-concept $\left(p=.000 ; \eta_{p}^{2}=.017\right)$ all improved significantly over this seven-month period, although the interpretation of the partial eta-squared values shows that the effect size of the differences is considerably small in each case (Draper, 2011).

Secondly, with regard to the interaction between group and time, it should be noted that there were no statistically significant differences between the groups for any of the dimensions over time ( $p=.132$ to $p=$ .980). In other words, the intervention on the experimental group was no more effective than the activities completed by the control group at improving any of the dimensions of the students' self-concept.

\section{Discussion}

The main aim of this research has been to analyse the effect of flipped classroom methodology on primary school students' self-efficacy. To this end, the study examined a control group and an experimental group with an intervention lasting seven months.

The results obtained show that students who took part in the flipped classroom intervention (experimental group) did not did not display greater increases or decreases in any of the self-efficacy dimensions than the students who took part in an intervention using other types of methodologies (control group). This finding is in keeping with other research that did not support flipped classroom methodology as more effective than other methodologies in order to improve different psychological constructs (Ferriz et al, 2017; Chun \& Heo, 2018)

Unless future studies show otherwise, this finding proves that while the flipped classroom could be a suitable methodology for primary school, other methodologies can lead to similar results. In view of this result, teachers can choose the most suitable method for each educational situation. Hence, those teachers who might find it difficult to apply flipped classroom methodology because of the considerable preparation involved can apply other methodologies that work just as well.

Additionally, it should be noted that while selfconcept is normally a stable construct, in this case both the experimental and control group improved their 
social, emotional and family self-concept over the course of the intervention, demonstrating that selfconcept can also be modified in the medium term. This finding points to a mix of stability and relative malleability of self-concept, an idea often borne out by other scientific studies (Markus \& Kunda, 1986; Markus $\&$ Wurf, 1987). Academic and physical self-concept did not improve during the intervention in either of the groups, remaining stable at both measurements.

In view of these results, future studies could shed some light on how this methodology alters the selfconcept of teenagers and university students. These studies could help us to compare outcomes and delve further into this topic. Likewise, there is still a long way to go to determine the applicability and the effectiveness of the use of this methodology with children, not only on their academic performance, but also on other psychological and social constructs. For instance, the effects of flipped classroom techniques on primary education students' autonomy or on the development of their digital competence are topics which have yet to be analysed.

Lastly, it is worth noting some of the limitations of this research. Firstly, it is impossible to assume the existence of a causal relationship between the intervention and the self-concept results. Education is a complex field in which an important number of variables could lead a person's self-concept score. Self-concept is not only subject to the influence of a given teacher's methodology, but can also be affected by a wide range of occurrences in a person's life. In addition, and linked to this limitation, some methodologies were shared by both groups (cooperative learning, project-based learning, etc.). In this sense, both groups could have been exposed to similar interventions, with the only difference being that the experimental group also used flipped classroom methodology.

Next, it is worth mentioning that a large percentage of the sample was made up of fifth-grade and sixthgrade students, and therefore fourth-grade students were not as well represented.

Finally, with regard to the sample's origin, it is worth underlining that participants came from only a few of the autonomous communities in Spain, while other important regions of Spain such as Catalonia and Andalusia did not take part in this study. Thus, there is not a balanced representativeness of the autonomous communities of Spain.

\section{Author's disclosure statement}

The author declares no conflicts of interest.

\section{References}

Aidinopoulou, V. \& Sampson, D. G. (2017). An Action Research Study from Implementing the Flipped Classroom Model in Primary School History Teaching and Learning. Educational Technology \& Society, 20 (1), 237-247.
Alsancak, D. \& Özdemir, S. (2018). The Effect of a Flipped Classroom Model on Academic Achievement, Self-Directed Learning Readiness, Motivation and Retention. Malaysian Online Journal of Educational Technology, 6 (1), 76-91.

Arnold-Garza, S. (2014). The flipped classroom teaching model and its use for information literacy instruction. Communications in information literacy, 8 (1), 7-22.

Baker, J. W. (2000). The "Classroom Flip": Using web course management tools to become the guide by the side. In J. A. Chambers (Ed.), 11th International Conference on College Teaching and Learning (pp. 9-17). Jacksonville, Florida: Florida Community College.

Bergmann, J. \& Sams, A. (2012). Flip your Classroom: Reach Every Student in Every Class Every day. Washington, EEUU: ISTE.

Bonett, D. G. \& Wright, T. A. (2014). Cronbach's alpha reliability: Interval estimation,hypothesis testing, and sample size planning. Journal of Organizational Behaviour, 36 (1), 3-15.

Cheung, G. W. \& Rensvold, R. B. (2002). Evaluating goodness-of-fit indexes for testing measurement invariance. Structural Equation Modeling, 9 (2), 233255.

Chou, L.Y. (2018). The effect of Flipped Classroom on self-efficacy and satisfaction of computer auditing. In L. Barolli \& T. Enokido (Eds.), Innovative Mobile and Internet Services in Ubiquitous Computing: Advances in Intelligent Systems and Computing (pp. 841-845). Cham, Switzerland: Springer.

Chun, B. A. \& Heo, H. J. (2018). The effect of flipped learning on academic performance as an innovative method for overcoming Ebbinghaus forgetting curve. In M. Krishnamurthi \& M. Ilinuma (presidency), International Conference on Information and Education Technology, 56-60. Osaka, Japan: ACM.

Díaz-Garrido, E., Martín-Peña, M. L \& Sánchez-López, J. M. (2017). El impacto del flipped classroom en la motivación y en el aprendizaje de los estudiantes en la asignatura Dirección de Operaciones. Working papers on Operations Management, 8 (Especial Issue), 15-18.

Eryilmaz, M. \& Ahmed, A. (2017). An adaptive teaching model for Flipped Classroom. International Journal on Recent and Innovation Trends in Computing and Communication, 5 (7), 35-39.

Esnaola, I., Rodríguez, A. \& Goñi, E. (2011). Propiedades psicométricas del cuestionario de Autoconcepto AF5. Anales de Psicología, 27 (1), 109-117.

Fernández-Zabala, A., Rodríguez-Fernández, A. \& Goñi, A. (2016). The structure of the social self-concept (SSC) Questionnaire. Anales de psicología, 32 (1), 199-205.

Ferríz, A., Sebastià, S. \& García, S. (2017). Clase invertida como elemento innovador en Educación Física: Efectos sobre la motivación y la adquisición de aprendizajes en Primaria y Bachillerato. In R. Roig (Ed.), Investigación en docencia universitaria. Diseñando el futuro a partir de la innovación educativa (pp. 211233). Barcelona, Spain: Ediciones Octaedro. 
FLN (2014). The Four Pilars of F-L-I-P. Flipped Learning. Retrieved from https://flippedlearning.org/ wp-content/uploads/2016/07/FLIP_handout_FNL_ Web.pdf

Galindo-Domínguez, H. (2018). Un meta-análisis de la metodología Flipped Classroom en el aula de Educación Primaria. EDUTEC, revista electrónica de tecnología educativa, 63, 73-85.

García, F. \& Musitu, G. (2001). AF-5. Autoconcepto Forma 5. Madrid, Spain: TEA Ediciones.

Hooper, D., Coughlan, J. \& Mullen, M. R. (2008). Structural Equation Modelling: Guidelines for Determining Model Fit. The Electronic Journal of Business Research Methods, 6 (1), 53-60.

Hwang, G.J., Lai, C.L. \& Wang, S.Y. (2015). Seamless flipped learning. A mobile technology-enhaced flipped classroom with effective learning strategies. Journal of Computers in Education, 2 (4), 449-473.

Ibrahim, M. (2014). Students' Learning Outcomes and Self-Efficacy Perception in a Flipped Classroom. In T. Bastiaens (Ed.), World Conference on E-Learning in Corporate, Government, Healthcare and Higher Education (pp. 899-908). California, EEUU: AACE.

Lage, M.J. Platt, G.J. \& Treglia, M. (2000). Inverting the Classroom: A gateway to creating an inclusive learning environment. Journal of Economic Education, 31 (1), 30-43.

Lai, C.L. \& Hwang, G.J. (2016). A self-regulated flipped classroom approach to improving students' learning performance in a mathematics course. Computers \& Education, 100, 126-140.

Markus, H. \& Kunda, Z. (1986). Stability and malleability of the self-concept. Journal of Personality and Social Psychology, 51 (4), 858-66.

Markus, H. \& Wurf, E. (1987). The dynamic self-concept: A social psychological perspective. Annual review of psychology, 38 (1), 299-337.

Marsh, H. \& Rhonda, G. (2002). The pivotal role of frames of reference in academic self-concept formation: The "big fish-little pond" effect. In F. Pajares \& T. Urdan (Eds.), Academic motivation of adolescents (pp. 83-123). Greenwich, England: Information Age Publishing,

Mohammed, A. (2017). Effectiveness of Using Flipped Classroom Strategy in Academic Achievement and Self-Efficacy among Education Students of Princess Nourah bint Abdulrahman University. English Language Teaching, 10 (4), 67-77.
Mohanty, A., \& Parida, D. (2016). Exploring the Efficacy \& Suitability of Flipped Classroom instruction at school level in India: A pilot Study. Creative Education, 7, 768-776.

Moos, D. C., \& Bonde, C. (2016). Flipping the Classroom: Embedding Self-Regulated Learning Prompts in Videos. Technology, Knowledge and Learning, 21(2), 225-242.

Prieto, A. (2017). Flipped Learning. Aplicar el modelo de Aprendizaje Inverso. Madrid, España: Narcea.

Ruiz, J., Sánchez-Rodríguez, J. \& Sánchez-Rivas, E. (2014). Flipped Classroom, Una experiencia de enseñanza abierta y flexible. In F. Martínez (Presidency), XVII EDUTEC International Congress 2014: El hoy y el mañana junto a las TIC. Córdoba, Spain: EDUTEC.

Sedraz, J. C., Zambom, E., Lins, R., Cavalcanti, J. L., Fonseca, F. (2018). Effects of learning analytics on students' self-regulated learning in flipped classroom. International journal of information and communication technology education, 14 (3), 91-107.

Tao, S.Y., Huang, Y.H. \& Tsai, M.J. (2016). Applying the Flipped Classroom with Game-Based Learning in Elementary School Students' English Learning. In C.K. Chang, G.J. Hwang, L. Chen, J. Cheng, T.H. Huang \& D.S. Shyu (Presidency), 2016 International Conference on Educational Innovation through technology. Taiwan, China.

Toh, T., Tengah, K., Shahrill, M., Tan, A. \& Leong, E. (2017). The Flipped Classroom strategy: The effects of Implementation at the elementary school level mathematics lessons. In TIIKM (Ed.), $3^{a}$ Ed. del International Conference on Education 2017, Models of Global Education and Education Mobility for the 2020's. Kuala Lumpur, Malasia.

Tsai, C.W., Shen, P.D. \& Lu, Y.J. (2015). The Effects of Problem-Based Learning with Flipped Classroom on Elementary Students' Computing Skills: A case Study of the Production of Ebooks. International Journal of Information and Communication Technology Education, 11 (2), 32-40.

Uzunboylu, H. \& Karagözlü, D. (2017). The emerging trend of the flipped classroom: A content analysis of published articles between 2010 and 2015. Revista de Educación a Distancia, 54, 1-13.

Xin-Yue, Z. (2016). Motivation in a Flipped Classroom, a Case Study of Teaching Oral English in a Vocational College in Mainland China. English teaching, 13 (6), 460-567. 